$\xi=$

\title{
A Review of Structural Equation Model for Construction Delay Study
}

\author{
Mohd Zakwan Ramli ${ }^{1 *}$, Marlinda Abdul Malek ${ }^{2}$, Mohamad Zaki Muda ${ }^{3}$, Zulkhairi Abd Talib ${ }^{4}$, Nor Syahirah \\ Azman $^{5}$, Nur Farah Syazana Mohamad Fu'ad ${ }^{6}$, Mohd Hafiz Zawawi ${ }^{7}$, and Herda Yati Katman ${ }^{8}$ \\ ${ }^{1}$ Department of Civil Engineering, College of Engineering, Universiti Tenaga Nasional, Kajang, Selangor, Malaysia. \\ ${ }^{2}$ Institute of Energy Policy Research (IEPRe), Universiti Tenaga Nasional, Kajang, Selangor, Malaysia. \\ ${ }^{3}$ Project Execution Department, Energy Ventures Division, Tenaga Nasional Berhad, Petaling Jaya, Selangor, Malaysia. \\ *Corresponding author E-mail: zakwan@ uniten.edu.my
}

\begin{abstract}
Structural Equation Modelling (SEM) has been widely used in science social area compared to construction engineering and management field especially in area of delay construction. SEM is a second generation multivariate analysis that has an advance features compare to first generations of analysis tools. First generation techniques suffer with some assumptions such as error measurement is neglected, only observed variable allowed, only for simple model and other limitations. In construction delay study, comprehensive and complex analysis which involves hidden variables need to be considered to get precise results. Therefore, the main objective of this paper is to review the importance of applying SEM for construction delay study. Various papers which were taken from construction delay and construction management studies has been reviewed to observe the suitability of SEM for construction delay study. Outcome of this review reveals that SEM can include latent variable in the analysis model and consider of error measurement as integral part of the model as well as simultaneously analyse theory and measurement in a structural model while it is unobtainable for first generation techniques. This review proves that SEM can be an appropriate analysis tool for construction delay study.
\end{abstract}

Keywords: Construction delay; construction management; multivariate analysis; error measurement; Structural Equation Modelling (SEM)

\section{Introduction}

Delay is known as a time disruption during the construction project. Interference during projects may prolong the project duration and exceed the specified date. According to [1], delay factors are critical factors that lead to cost overruns. Furthermore, claims, disputes, and additional costs are the consequences of the project delays [2]. In order to achieve a successful project, it is crucial to identify the factors that contribute to project delays. Therefore, delay analysis is required, so that the delay issues can be resolved before it occurs or it will be beneficial for another project in future.

The construction sector has a pivotal role in economic growth in Malaysia. Results from the earlier study demonstrate a strong and consistent association between construction sector and economic growth in Malaysia [3]. Improvement of the economic sector in the country relies on the development of infrastructure. Poor infrastructures are the biggest challenge for one country to expand which it may lead to the unwillingness of investor in performing their business activity. Narrow roads, lack of transportation, poor water quality, and electricity problems are amongst of the issues that require attention in order to enhance the living standard of society and improve healthy lifestyle for the sake of the country and worldwide. Nevertheless, a large-scale infrastructure is normally extremely complex. Thus, the government has invested a big amount of money on infrastructure projects. Part of infrastructure projects is including railway, roads/bridges, ports, hydropower plants, and water/wastewater treatment plants.
However, major infrastructure plan always has an obstacle and issues that raised such as delays in project completion. There are several mega construction projects that have been developed in Malaysia but suffered from delay problems. Large infrastructure projects that suffer from delays are common but without proper management and supervision, it will cause cost overrun. Huge losses have been reported during a construction of Kuala Lumpur's airport terminal, KLIA2 and eventually faces with delay problems [4]. Due to modifications terminal concept during construction, ultimately it costs RM4 billion rather than RM1.7 billion at the initial project as planned [5]. Another mega project in the country, which is the project of a hydropower plant in Bakun, Sarawak also experienced huge delay and cost overrun [6]. The longest bridge in Southeast Asia and also known as the second bridge in Pulau Pinang of Malaysia was scheduled to be completed in 2011 but the bridge only available for people to use in 2013 [7]. The bridge project was suffered from two years delays time and the cost had increased about RM1.5 million because of location issues, increasing of material cost and other unexpected events [8][9].

Schedule control is the main key to a successful project [10]. Time overruns give negative impacts on the project and all the involved construction parties. The overall project performance will decrease and competency of involved workers and professionals will be doubtful. According to current trend, there is an increasing demand of researchers in implementing SEM for various study area. SEM is a powerful tool in analysing multivariate analysis especially for second generation technique. Even though there were positive increment number of construction management study using SEM, there were limited study that applied SEM for 
construction delay. In order to achieve a comprehensive outcome, complex analysis which involves hidden variables are essential for construction delay study.

Most of previous studies, only focusing on the identifying of the delay factors and quantified the ranking of importance level based on degree of severity. First generation techniques such as factor analysis and regression modelling were the most frequent analysis method that used to evaluate the significance of the delay factors [11][12][13][14]. Since, first generation techniques encounter few limitations, for example, low ability to illustrate causal or complex modelling, failed to include latent or unobservable construct in the causal modelling, measurement error is neglected and more therefore, structural equation modelling, SEM from second generation technique is well suited to overcome the limitations. Therefore, the main objective of this paper is to review the importance of applying SEM for construction delay study.

\section{Multivariate Analysis}

Study of construction delay may include the determining of the interactions between indicators, independent variables and dependent variables. This may involve more than two variables which at this point, multivariate data analysis method is needed. All statistical techniques were include in multivariate analysis where it must involve more than two variables that simultaneously analysed [15]. There are several types of multivariate techniques that can be applied. Hence, an appropriate consideration of multivariate method is crucial in this study. Multivariate analysis consist of two generations which are first generation and second generation techniques as illustrated in Table 1[16].

Table 1: Type of Multivariate Analysis [16]

\begin{tabular}{|c|c|}
\multicolumn{1}{c|}{ Table 1: Type of Multivariate Analysis [16] } \\
\hline \multirow{4}{*}{ First } & Method \\
\cline { 2 - 2 } Generation \\
Technique & Factor Analysis \\
\cline { 2 - 2 } & Cluster Analysis \\
\cline { 2 - 2 } & Multidimensional Scaling (MDS) \\
\cline { 2 - 2 } & Logistic Regression \\
\cline { 2 - 2 } Second & Multiple Regression \\
Generation & Structural Equation Model, SEM \\
Technique & - Covariance Based \\
& - Partial Least Square \\
\hline
\end{tabular}

\subsection{First Generation Techniques}

First generation of statistical method analysis are incompetent to illustrate complex modelling or causal modelling. For example, standard regression models only allow for detailed modelling of direct effect between independent towards dependent variables. First generation techniques also cannot directly test mediation effects and moderation effects. Other than that, the primary problem of first generation techniques is measurement error. If measurement is made with error, it might cause misinterpreting or underestimating the strength of relationships between constructs [17]

Causal modelling explicitly explains and estimate the relationships among variables so that the changes and direction of effects are identified. It might be useful for researchers to increase the quality of time management in construction project. For example, causal modelling can explain and predict the key factors that caused construction delay [18], thus improve construction project performance. Nevertheless, first generation techniques suffer from few assumptions: [19] (1) model structure must be simple, (2) all variables must be observable (eg., latent variable), and (3) measurement error is neglected. Despite of those facts, first generation techniques only can analyse in one layer of relationships between independent and dependent variables at a time [19]. Hence, the analysis need to run separately many times until it achieve a fit model [19]. This is however, there is a solution to overcome restriction of latent variables by removing latent variable scores, LVS during a factor analysis [20]. Instead of full factor, LVS can be used as a proxy (observed) variables through subsequent tests of causal relationships (regressions). Yet, LVS and even a fully latent factor still cannot account for measurement error [20].

When the analysis include latent variables, discriminant and convergent validity test of latent variables must be run first before test the theoretical model by using separate analysis [20]. Somehow, discriminant and convergent validity analysis (measurement items) and nomological analysis (theoretical model) must be tested in a separate assessment namely two-step approach [20][21]. Normally, after factor analysis for measurement items are established, then causal relationships in a subsequent analysis are tested. However, separation analysis may cause mistaken prediction, measurement and explanations, as a matter of fact, theory and measurement are excellent to handle with together to avoid restriction of measurement error in a subsequent analysis [20].

Normally, first order construct are applied to model causal relationship where latent construct has a direct reflective or formative relationship to indicators [20]. Therefore, to evaluate the relationships, factor analysis can be implemented. This techniques can be used to evaluate the effect of each indicator on the constructs [22]. Factor analysis is functional to test hypotheses about the similarity between scores on observed (manifest) variables, or indicators, and hypothetical constructs (latent variables) consider to affect those scores [23]. However, all these techniques are constrained by assumption of causal relation only between latent variables and indicators. Whilst, cluster analysis is a statistical method that involves in assigning a set of numerous objects of similar to each other (relationship) or dissimilar from (or unrelated to) into groups (called cluster) [17]. Normally, cluster analysis is part of sequence from factor analysis. After factor analysis reduces the dimensions and number of variables, cluster analysis will perform to identify groups.

According to [16], to test the relationship between the latent variables and indicators, cluster analysis and factor analysis can be implemented. These method of statistical analysis can assess the relationship between the manifest variables (indicators) and latent variables (group) by correspondence of objects within a group (cluster) and interrelation between scores on indicators and latent variables (construct) [16]. Nevertheless, the analysis is incompetent to describe the relationships of the underlying attributes [24]. All these techniques also only can define correlation among indicators and latent variables. Despite of these, they also cannot perform a complex causal relationship which may involves many variables in a model. Even though correlation among complex indicators and latent variables towards dependent variable by direct and indirect effects are established through factor and cluster analysis, assessment of relationship between independent variables and dependent variables are needed in most of research study. Hence, a subsequent analysis of causal relationships is required instead of factor and cluster analysis.

There are few methods that relevant to evaluate correlation between variables in project delay such as multiple regression analysis, multivariate analysis of variance, (MANOVA) and analysis of variance, (ANOVA). These methods can identify the categories and level degree of relationship between the dependent and the independent variables of the study. For instance, MANOVA and multiple regression analysis can be used to test the relationships of independent and dependent variables. However, the test only done directly and only limited for analysing the effect of independent variables towards dependent variables [25]. Furthermore, testing of causal relationships between independent and dependent variables do not account for measurement error [26]. First generation technique only assessed measurement error in a reliability analysis but then the errors are neglected in the subsequent analysis of the theoretical model [26]. Moreover, regression analysis is perfectly fit with simple model which 
involved a small number of independent and dependent variables and also with high normalised data [20]. Therefore, all these methods are not appropriate to consider in research study of construction delay due to assumption made and limited implementation. Advance features such as mediation and moderation effect are necessary in a study of construction delay. For example, each key causes might has direct causal effect with the latent variable and indirect causal effect towards dependent variable [18] and the result analysis may help to minimize the effect of delay construction.

$Y=a+b_{1} X_{1}+b_{2} X_{2}+b_{n} X_{n}+e$

Equation (1) explained independent variable, $\mathrm{X}$ gives impact to dependent variable, Y [25]. Nevertheless, in theory testing, many research states that there is indirect effect or mediation of an independent variable towards dependent variable that transmitted through one or more mediator variables [25]. Instead of to evaluate correlation among variables, regression analysis method also can adopt mediation technique but it is restricted to assumption of no measurement error in the mediator [27].

Interaction effects is part of moderation effects. Moderation effects is useful for complex model in research design. Analysis of variance such as ANOVA and moderated multiple regression, MMR are the traditional methods that used to test the interaction effects. However, the main problem to detect interaction effects is measurement error. Those two techniques of MMR and ANOVA assume likely small or no measurement error in their analysis and have no ability to detect such interaction effects [26]. Measurement error have tendency to reduce the ability in detecting moderating effect and an accurate estimation of the effects are rarely achieved [28]. If the detection is occurred, the results of moderator analysis may be not accurate due to measurement error [26]. Hence, in moderator analysis, measurement error must be take into account during at the early stage of scale construction and also when estimate the interaction effects during statistical analysis [26].

In order to enhance and minimize problems and impacts of construction delay, explicit research with rich analysis are essential. SEM analysis tool able to incorporate measurement error in the estimation analysis as well as allow to model chain of causal effect and indirect effect, include latent variables and advance analysis in detailed modelling simultaneously. Hence, extensive and flexible causal modelling by second generation technique of structural equation modelling, SEM is relevant to consider in the construction delay.

\subsection{Second Generation Techniques}

Second generation techniques involve of structural equation modelling, SEM. It is an improvement application of factor analysis and regression analysis [29]. They are being analysed simultaneously for theory testing. SEM also perform as an advance statistical tool that used to evaluate causal modelling with complex relationship between one or more dependent and independent latent variables.

There are two types of variables that commonly applied in SEM which are manifest variable and latent variable. Manifest variables are variables that can be only directly measured or observed. Whereas, latent variables are hypothetical or also known as theoretical constructs of the model that cannot be measured directly. Therefore, in SEM, each latent variable or unobservable latent construct can be estimated by several of observed variables as a proxy [20]. These proxies can also be called as manifest variables or indicators and all these variables can be directly measured. All these indicators are measured by using several kinds of scale items such as questionnaires. The magnitude of latent variables can be approximated based on responses from the scale items [30].
Two basics component of SEM are the structural model and the measurement model [15]. Structural model comprises of path model which connect independent variables to dependent variables while the measurement model consists of indicators that relate to independent variables.

\section{Advantages of SEM}

\subsection{Incorporate Latent Variable}

The main ability of SEM is it enable researchers to include latent variables into the analysis [20]. Latent variables are involved in the SEM to account for measurement error and thus, improve the accuracy of estimation [15]. The relationships among latent variables are certainly obtained by SEM compare to other analysis method that cannot measures the correlation of latent variables. Even though multiple regression analysis is able to analyse relationships of independent and dependent variables, but it has restriction that the analysis only involve observed (measured) variables and neglect measurement error [30].

\subsection{Simultaneous Analysis}

First generation statistical modelling such as factor analysis, cluster analysis, MANOVA, and multiple regression analysis are constraint with certain restrictions such as ignore the measurement error as well as separation analysis of theory and measurement. While, second generation methods allow for multiple number of relationships between endogenous and exogenous variables including latent variables which is called structural model, being analysed simultaneously. In addition, the assessment of measurement model also in the same analysis.

Two step approach is a typical assessment applied by first generation technique which separate analysis of theory and measurement in an analysis. However, there are certain implications arise such as bias, hence, joining theory and measurement in analysis model is appropriate. SEM come out with resolution to overcome those limitations. SEM is a single, systematic and comprehensive analysis that analyse the relationships among multiple independent and dependent constructs simultaneously and assessment of observed measurement on the expected latent constructs also in the same analysis [21]. In SEM, convergent and discriminant validity test to test latent constructs are known as the measurement model, whereas, testing of causal relationships in the theoretical model are called the structural model [31]. Combination analysis of theory and measurement will take into account for errors of the observed variables to be analysed as part of the model and achieved an accurate estimation better than first generation techniques [20][21].

\subsection{Mediation Analysis}

Complex model in SEM include latent variables based on multiitem indicator variables, formative and reflective variables, chain of effect (mediation) and multiple stages or levels of constructs. Mediation analysis often called as mediating effect or indirect effect. The primary aspect of mediating effect is that it involves a third variable that act as an in-between role in the relationship between the independent and dependent variables [32]. Latent variables can be analysed in a causal modelling (or path analysis) in SEM and it allows researchers to evaluate complete causal networks. It also provides mediation method that can cope with complex causal modelling. For example, as illustrated in Figure 1, the variables is not limited to only $\mathrm{X}$ and $\mathrm{Y}$, which is this simple cause-effect relationship are easily estimated. In addition, more variables can add into the path diagram. The effects of $X \rightarrow Y$ and $\mathrm{Z} \rightarrow \mathrm{Y}$ (direct effect) can be predicted as well as the indirect effect of $\mathrm{X}$ on $\mathrm{Y}$ through $\mathrm{Z}$. In other words, as shown in Figure 2, the 
effect of the independent variable $\mathrm{X}$ on the dependent variable $\mathrm{Y}$ is mediated by a third variable, $\mathrm{Z}$, as the mediating variable or mediator [32].

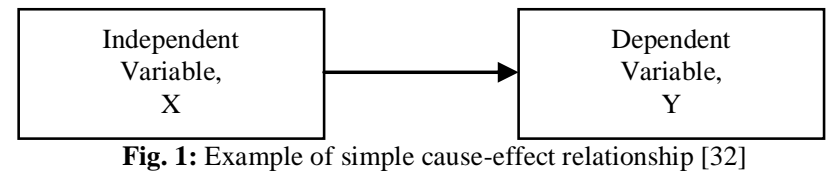

Fig. 1: Example of simple cause-effect relationship [32]

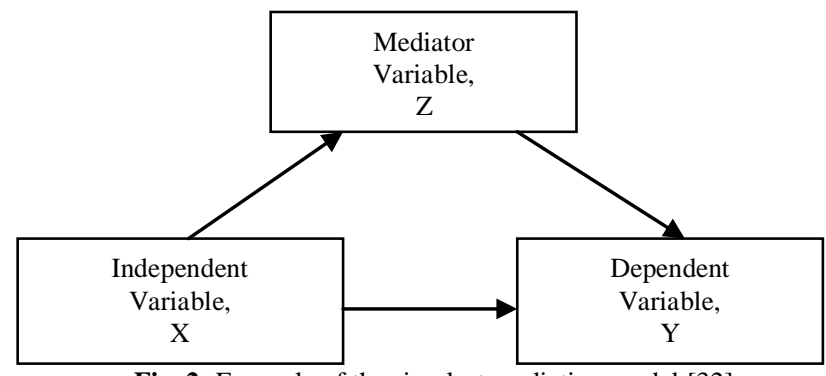

Fig. 2: Example of the simplest mediation model [32]

\subsection{Moderation Effects}

Moderation effects involve a moderator variable that influence the strength of two other constructs. A moderator can be a qualitative or quantitative variable that affects the direction or strength of a causal relationships between an independent variable and a dependent variable [27]. In order to avoid problems of measurement error during analysing interaction effects, a productindicator approach, Kenny-Judd model has been proposed as a solution [33]. Covariance based technique, such as LISREL 8 can perform an estimation with Kenny-Judd model easily [34]. Other than that, AMOS, one of CB-SEM software, has a design features that will simply analyse categorical (grouped) moderators, such as gender [20]. Since SEM can incorporate measurement error, it can be the best alternative technique compare to first generation techniques to assess moderator analysis.

\section{Methods of SEM}

Several approaches have been used to perform path analysis with latent variables such as Covariance-based SEM (CB-SEM), Partial Least Squares SEM (PLS-SEM), Generalized Structured Component Analysis (GSCA) and Nonlinear Universal Structural Relational Modeling (NEUSREL). Thus, researchers has to consider the appropriate method depends on their characteristics that suit with the purpose of the study.

SEM covariance-based also known as LISREL, covariance structure analysis or latent variable analysis, are used modelling software tools such as LISREL [35], AMOS [36], EQS [37] and Mplus [38]. CB-SEM is a model of theory testing which is based on covariance matrices without focusing on explained variance.

While, Partial Least Squares SEM (PLS-SEM) is known as variance-based SEM or component-based SEM. It is being invented to maximize variance by using component weights for prediction and theory building [21][39]. Partial least squares can be performed by using software programs such as LVPLS, latent variables path analysis with partial least-squares, PLS-Graph, Smart- PLS and VisualPLS [40].

CB-SEM and PLS-SEM have been a common and traditional method that extensively applied by researchers to analyse causeeffect relations between variables which include latent variables in the analysis by using structural equation modelling. However, other approaches to SEM also available which are Generalized Structured Component Analysis (GSCA) and Nonlinear Universal Structural Relational Modelling (NEUSREL). Generalized structured component analysis have been proposed by [41] as another method to partial least squares for path analysis with components. It can be executed by using software package of
Visual GSCA or a web-based application, GSCA. GSCA has advantages over PLS as it is provided with an overall measure of model fit and it can deals with more diverse path analyses [41]. NEUSREL is another way to perform structural modelling. It can be implemented by NEUSREL's Causal Analytical software and suitable for nonlinear relations and interactions among model constructs that are not hypothesized by a researcher [42].

Nevertheless, inadequate literature found about application of GSCA and NEUSREL in SEM. Researchers may find it challenging to understand and implement these approaches in analysing SEM. Thus, the well-known SEM approaches of CBSEM and PLS-SEM are appropriate methods that can be consider in this research area. Table-3 shows the comparison between CBSEM and PLS-SEM based on several criteria.

\subsection{CB-SEM and PLS-SEM}

CB-SEM or PLS-SEM are not competitive methods but they are a complimentary method. The key elements to consider either CBSEM or PLS-SEM that suitable to apply in the research study is their characteristics and the research goal [43]. Even though most of the advantages in CB-SEM also applied in PLS-SEM, there are certain features that has different approaches and purposes. PLSSEM has benefit in building theory compare to first generation and CB-SEM, whilst, CB-SEM has the ability to validate model, contrary to PLS-SEM [20]. Table 2 shows the characteristics of CB-SEM and PLS-SEM.

\subsection{Objectives}

The objective of CBSEM is to indicate that the null hypotheses is insignificant [21]. CB-SEM is based on covariance matrix where it tends to explain the relationships of measured variable and constructs [39]. While, the goal of PLS-SEM is to minimize the amount of unexplained variance which maximizes $\mathrm{R}^{2}$ and significant t-values, hence denying the null hypothesis of no-effect [44].

CB-SEM specifies in theory testing, theory confirmation or comparison of alternatives theories, whereas, PLS-SEM specifies in predicting key target constructs, identifying key-driver construct; exploratory or an extension of an existing structural theory [45]. CBSEM is led by theory, instead of data results because of the indicators are valid measurements of the constructs and well determined in the analysis model [46].

\subsection{Constructs Specification}

CBSEM is more to confirmatory model which tends to depict the relationships between indicators and constructs as well as for theory confirmation or comparison of alternative theories. Whereas, PLS-SEM is intends to exploratory model and for theory development [47].

Table 2: The difference between CBSEM \& VBSEM [16][34]

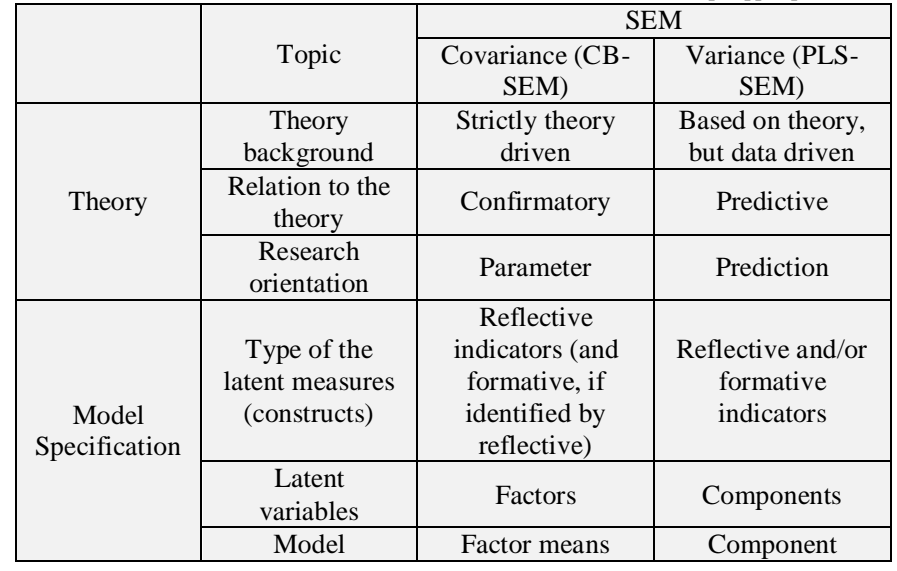




\begin{tabular}{|c|c|c|c|}
\hline & parameters & & weights \\
\hline & $\begin{array}{c}\text { Structure of } \\
\text { unobservable }\end{array}$ & Indeterminate & Determinate \\
\hline & $\begin{array}{c}\text { Model } \\
\text { complexity }\end{array}$ & $\begin{array}{l}\text { Low or medium } \\
\text { complexity due } \\
\text { to small number } \\
\text { of indicators } \\
\text { allowed }\end{array}$ & $\begin{array}{l}\text { High complexity } \\
\text { due to large } \\
\text { numbers of } \\
\text { indicators } \\
\text { allowed }\end{array}$ \\
\hline Sample & Sample size & $\begin{array}{c}\text { At least } 100-150 \\
\text { cases }\end{array}$ & $\begin{array}{l}\text { - Ten } \\
\text { observations } \\
\text { multiplied with } \\
\text { the construct } \\
\text { that has } \\
\text { highest } \\
\text { number of } \\
\text { indicators } \\
\text { - The } \\
\text { endogenous } \\
\text { construct with } \\
\text { the largest } \\
\text { number of } \\
\text { exogenous } \\
\text { constructs, } \\
\text { multiplied } \\
\text { with ten } \\
\text { observations } \\
\end{array}$ \\
\hline \multirow[t]{2}{*}{ Software } & \multirow{2}{*}{$\begin{array}{c}\text { Data } \\
\text { distribution } \\
\text { assumption }\end{array}$} & $\begin{array}{l}\text { Normally } \\
\text { distributed }\end{array}$ & $\begin{array}{l}\text { "Soft" modelling } \\
\text { (no assumption } \\
\text { about } \\
\text { data distribution) }\end{array}$ \\
\hline & & $\begin{array}{l}\text { LISREL, AMOS, } \\
\text { etc. }\end{array}$ & $\begin{array}{c}\text { Smart PLS, SPSS } \\
\text { (PLS module), } \\
\text { etc. }\end{array}$ \\
\hline
\end{tabular}

Direction of the relationship between latent and manifest variables in order to establish a measurement model must be specified either reflective or formative. In CB-SEM and even in first generation techniques, all indicators are assumed to be a reflective indicator. A reflective indicator is an observed variable that depend on latent construct [19]. Reflective indicators is an effect of latent construct or a consequent indicator [48]. All the indicators are interchangeable, therefore adding or removing one or more indicators gives no effect to validity of latent construct [49]. In PLS-SEM, indicators can be identified as reflective and formative in a measurement model. Formative indicator is a cause of latent construct or a causal indicator [48]. Combination of all indicators describe the latent constructs, so it is easily affected by number and type of indicators of targeted latent construct [49]. Since they are not interchangeable, adding or eliminating one of the indicator may potentially change the conceptual of the latent constructs [49]. Referring to Figure 3 [50], reflective indicator indicates that an arrow pointing to square shape from an oval shape which represent as indicator and latent construct. While, vice versa for formative indicator.

Assumptions of all indicators are reflective in CB-SEM and first generation techniques may cause severe modelling error [51]. Therefore, it is important to identify the appropriate type of indicators in the measurement model before analyse the model. If the model comprises both reflective and formative indicator, PLSSEM must be a selection of SEM method. Otherwise, if all the indicators are specified as reflective, then both CB-SEM and PLSSEM can be an option of SEM model that meet the criteria in research study.

\subsection{Model Parameters and Data Distribution}

CB-SEM follows maximum likelihood (ML) estimation method. Maximum likelihood covariance structure analysis was developed by [52] and extended by Wiley in 1973 [39]. However, ML suffered with certain assumptions such as only for normal multivariate data and large sample sizes is needed [17]. Sufficient number of sample size is necessary to prevent bias estimation, low statistical power and improper solutions. Besides that, at least 100-
150 sample sizes are required with a minimum number of indicator that must be not less than 3 for a model that have 5 or more constructs [15]. Hence, it is challenging to achieve model fit due to characteristics of confirmatory factor analysis, CFA that tends to remove relevant indicator variables and it is difficult to retain the minimum number of 3 indicators per constructs [15]. Whereas, ordinary least square (OLS) regression based method is the estimation procedure for PLS-SEM [45]. PLS-SEM intends to interpret relationships between constructs as well as relationships between constructs and indicators. Wider range of sample sizes and free data distribution are an attractive benefits of PLS-SEM that required by some of researchers [53] especially for confirmatory purpose. Parameter estimation in PLS-SEM are consistent at large [17]. In other words, as the number of indicators as well as sample size increases, the efficiency also improve. Moreover, PLS-SEM is flexible with data distribution. If the data is normal and samples are independent, it can calculate tvalues with bootstrapping technique. Otherwise, if the data is not normal or samples are not independent, jack-knifing or blindfolding can be used to calculate t-values [17][20]. PLS-SEM also reliable to deal with small sample sizes. However, it is still significant to determine the sample size accordingly to acquire reasonable power [20].
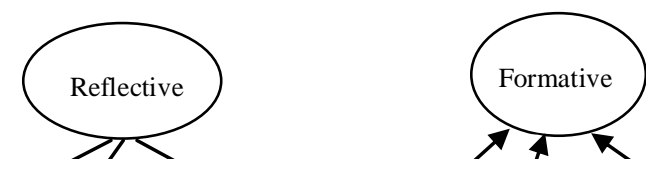

*Boxes represent measurement items

Fig. 3: Reflective and formative indicators [50]
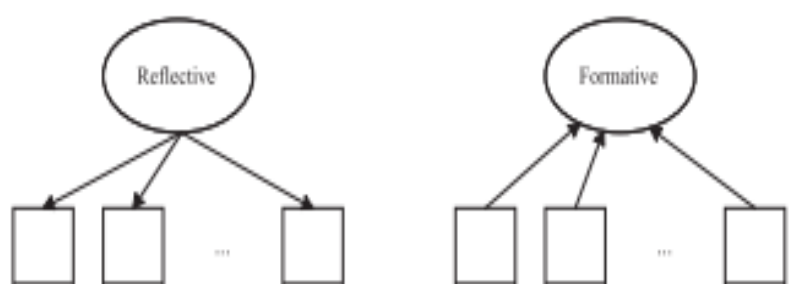

\subsection{Factor Indeterminacy}

The main difference about CB-SEM and PLS-SEM is the structure of unobservable or latent variables where CB-SEM is focusing on the residual structure, while in PLS-SEM, latent variable scores are explicitly estimated [46]. In precisely, model of the underlying latent constructs are indeterminate in CB-SEM and determinate in PLS-SEM [39]. Estimation of construct score in determinate model is developed to predict the dependent variable [54].

CB-SEM analysis often end with indeterminacy [20]. It can be problematic because indeterminate factors have improper loadings and capability of CB-SEM to allow imperfect measurement may cause a biased result [39][46]. Factor indeterminacy is a primary constraint in CB-SEM [44] due to nature of unobservable variable score is not unique. Initially model parameter of CB-SEM is estimate without using any case values of the unobservable variables score [45] which cause difficulty to estimate stable factor score [53]. Thus, CB-SEM is not appropriate for exploratory analysis. In contrast, PLS is suitable to perform exploratory analysis as it avoids factor indeterminacy by its assumption that total variance in the model's indicator variable is meaningful and it must involve in estimation of the construct scores [45]. Therefore, PLS can be used for exploratory and confirmatory analysis since it do not suffer by factor indeterminacy. 


\subsection{Moderation Effects and Complex Model}

Even though CB-SEM can incorporate a measurement model which the variables are measure with error and has gain improvement better than first generation techniques, it is not necessarily the best method to detect interaction effects. Nevertheless, software tools such as LISREL and AMOS cannot deal with moderating effects better like PLS do [26]. Besides, product indicator approach has been found to be more effectively in quantifying the moderation effects within PLS compared to CBSEM [54].

CB-SEM is suffered with low ability to deal with complex model. Moderate analysis normally increase the number of indicators and CB-SEM eventually will encounters with complex model. Therefore, CB-SEM will need a very large samples in order to acquire an accurate estimation. However, even with large number of sample sizes, indicators must not exceed 40 or 50 numbers in order to prevent occurrence of non-convergence (model failure) and improper solution [55]. In contrast, PLS has a characteristic of consistency at large, which is a large number of indicator variables are used to measure the latent constructs, so that biased estimation can be avoided [56]. In addition, large number of indicators help to reduce bias in PLS-SEM [45]. Furthermore, even in large numbers of indicators, the speed during computational time for estimation will be not interrupted in PLS which is unlike in CBSEM, where the estimation time may slowing down as the indicators go beyond 40 or 50 numbers [26]. Hence, PLS can simply perform model evaluation with increasing numbers of indicators and efficiently to evaluate complex model.

\subsection{Application of SEM in Project Construction Delay}

SEM has been widely used in science social area compared to construction engineering and management field. According to [57], it has been found an increasing trend of using SEM in construction industry as shown in Figure 4. SEM is an appropriate analysis tool for many of issues in research area within construction and management field [58]. Most of research issues consist of unobservable variables which are difficult to measure. Delay in project construction has been explored previously by researchers in many aspect such as project risk analysis, construction project success, and construction project performance, quantification of delay factors and also cause-effect of delay factors. However, delay construction research by using SEM in specifically are rare and limited.

Most of independent variables that has been used in analysis of construction delay involve variables that are difficult to measure. For example, a study of impact of delay factors on the completion of the government construction projects by developing a conceptual model have been done [14]. Final conceptual model after applying exploratory factor analysis, EFA are listed as (factor 1) competence, finance, and the approval procedure of the owner, (factor 2) external elements, (factor 3) extraneous nature and internal interaction of the project, (factor 4) competence of the consultant, (factor 5) competence, finance, and productive forces of the contractor, and (factor 6) contract terms. Analysis results by using multiple regression technique depicted that factors relating to contractor and owners were recognized as the most significant impact to project completion. The nature of some of these independent variables might be suited as unobservable or latent variables in a structure of SEM. For instance, factors that relating to contractor is a variable that cannot be measured directly and normally measured through proxies' variables such as improper construction method, financial problems, and etc. Nevertheless, independent variables in regression modelling are measured without error. Hence, latent variables are appropriately modelled through SEM as SEM allows measurement error in the analysis.

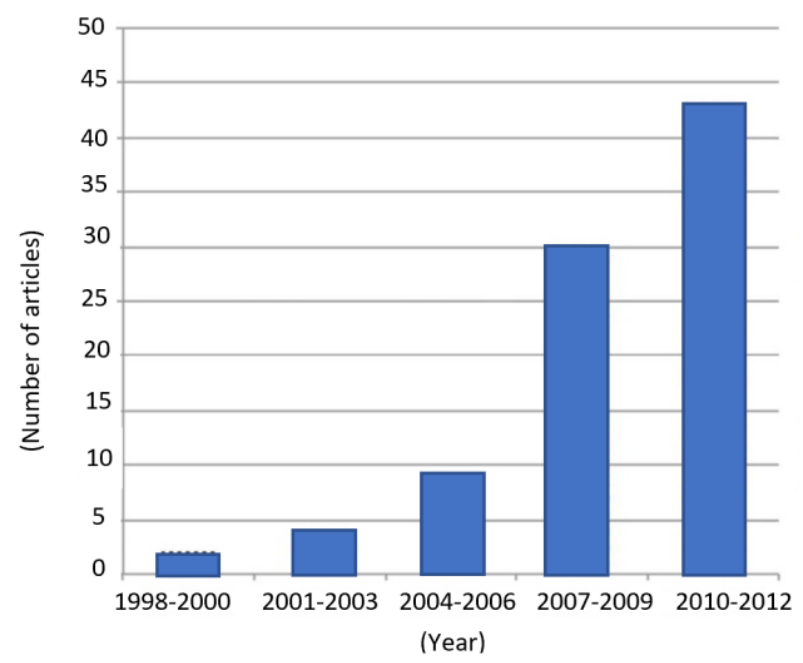

Fig. 4: Number of SEM-based articles by year [57]

In addition, SEM would be better in detecting indirect effect and interaction effect. However, most of researchers only focus on direct relationship and ignore the occurrence of mediating effect completely [32]. At the worst case, the assumption of irrelevant variable in the research may cause bias in the interpretation of analysis when the variable has no direct effect but the effect is actually mediated by other variable [32]. Till now not many research paper found in analysing mediator effect especially in delay construction. Moderator analysis also experience low number of application in construction engineering. Yet, there are few numbers have testing moderator in their research study. For example, a research about impact of interpersonal conflict on project performance has introduced political skill as a moderator role [59]. Political skill act as a moderator role on the relationship between negative emotions and project performance has been explored. Politically skilled in a project team members gives positive outcome in order to achieve performance of the project. It shows that moderator and mediating effect gives contribution in development of knowledge in the research. Therefore, their application in project construction delay by using SEM analysis tool will be meaningful. Since, CB-SEM is limited by few assumptions, therefore, PLS-SEM is the suitable analysis tool to be consider. Furthermore, PLS-SEM can provide more accurate estimation of mediating and moderating effect [54][60].

Other than that, SEM has the advantages and several advance features compare to the previous first generation techniques. This is comprise the assessment of higher order construct modelling. An analysis of second order in assessing the influence to delay construction project has been discovered by using CB-SEM analysis approach [61]. Even though both CB-SEM and PLSSEM applicable to analyse first order and second order construct of modelling, PLS are superior in complex model. PLS-SEM can tolerate with complex model that comprising several latent and manifest variables instead of CB-SEM that can only assess not more than 40-50 numbers of indicators. Number of indicators variables in research area of delay construction normally can up to more than 80 indicators [11][62][63].

Almost all of research study in delay construction project aim to find a solution to avoid delay or minimize the impact of delay as well as to improve time performance of construction project. Pertaining to these, determine the key factors or investigate the key predictors that directly or indirectly effect the delay construction (dependent) are some of an investigation needed in the research. Other than that, causal relationships among the variables will be examined and illustrated in a model for rich analysis. Identified of delay causes are wide-ranging among previous study and most of them only focusing on the most severe influenced key factor instead of to model the relationships among identified causes and all the variables [18]. The direction of the 
relationship between variables cannot be determined since the model is lacks of basic theory due to inadequate literature of delay construction using SEM model as a reference. Therefore, since PLS-SEM is suitable for theory development and testing, it allows for determination of latent constructs and variable relationships in complex model [47][64]. As the main function of theory development is to determine the measured variables, the relationships as well as the directions and strengths [64], PLSSEM is a suitable SEM model to consider in research study of delay construction.

\section{Conclusion}

Proper schedule strategy of construction project is essential to prevent delay issues. Previously, most of research study in delay construction often discussed about the key factors that caused the delay and provide a suggestion to avoid or minimize delay. With an advance second generation of multivariate analysis tool of SEM, rich analysis will be extracted and a comprehensive relationship among variables will be determined. The most significant features that distinguish between first generation approaches with SEM are SEM can include latent variable in the analysis model and take into account of error measurement as integral part of the model as well as simultaneously analyse theory and measurement in a structural model while it is unobtainable for first generation techniques. Since, study of delay construction is tend to exploratory and more to theory development, PLS-SEM seems to be a better choice as an analysis tool. Most of assumptions of the PLS-SEM meet the requirement of the research study such as it allow for complex model, flexible data distribution, tolerate with small sample size, and avoid factor determinacy. Furthermore, PLS-SEM is applicable with both confirmatory and exploratory approach. Hence, PLS-SEM is a suitable analysis tool for construction delay study. This review proves that SEM can be an appropriate analysis tool in a study of construction delay.

\section{Acknowledgement}

The authors acknowledge Tenaga Nasional Berhad and Universiti Tenaga Nasional on the fund provided for this research. Special thanks to those who contributed to this project directly or indirectly.

\section{References}

[1] G. J. Kikwasi, "Causes and Effects of Delays and Disruptions in Construction Projects in Tanzania," Australas. J. Constr. Econ. Build. Conf. Ser. Rev., vol. 1, no. 2, pp. 52-59, 2012.

[2] N. Braimah and I. Ndekugri, "Factors Influencing the Selection of Delay Analysis Methodologies," Int. J. Proj. Manag., vol. 26, pp. 789-799, 2008.

[3] R. Ali Khan, M. Shahir Liew, and Z. Ghazali, "Malaysian Construction Sector and Malaysia Vision 2020 : Developed Nation Status," Procedia - Soc. Behav. Sci., vol. 109, pp. 507-513, 2014.

[4] F. Beckers, E. Silva, N. Chiara, A. Flesch, J. Maly, and U. Stegemann, "A Risk - Management Approach to a Successful Infrastructure Project," Singapore, 2013.

[5] R. Ghazali, "Transport Ministry: KLIA2 Construction Never Experienced Cost Overruns," The Star Online, 2015. [Online]. Available:

https://www.thestar.com.my/news/nation/2015/05/19/klia2-no-costoverun-minsistry/. [Accessed: 05-Dec-2017].

[6] The Star, "Bakun Project Firms in Deal to Withdraw All Claims," The Star Online, 2014. [Online]. Available: http://www.thestar.com.my/business/businessnews/2014/08/13/bakun-project-firms-in-deal-to-withdraw-allclaims/. [Accessed: 17-Aug-2017].

[7] S. Zailani, H. A. M. Ariffin, M. Iranmanesh, S. Moeinzadeh, and M. Iranmanesh, "The Moderating Effect of Project Risk Mitigation Strategies on the Relationship Between Delay Factors and
Construction Project Performance Abstract," J. Sci. Technol. Policy Manag., vol. 7, no. 3, 2016.

[8] F. Z. Ariffin, "Jambatan ke-2 Dibuka Oktober," Utusan Online, 2013. [Online]. Available: http://ww1.utusan.com.my/utusan/Ekonomi/20130718/ek_01/Jamb atan-ke-2-dibuka-Oktober. [Accessed: 03-Jan-2018].

[9] R. Hassan and N. Z. Nordin, "Projek RMK-9 dikaji balik Jambatan Pulau Pinang lewat sebab kos, tanah, reka bentuk - PM,' Utusan Online, 2008. [Online]. Available: http://ww1.utusan.com.my/utusan/info.asp?y=2008\&dt=0423\&pub =Utusan_Malaysia\&sec=Muka_Hadapan\&pg=mh_01.htm. [Accessed: 03-Jan-2018].

[10] G. K. Pall, A. J. Bridge, M. Skitmore, and J. Gray, "Comprehensive Review of Delays in Power Transmission Projects," Inst. Eng. Technol., vol. 10, no. 14, pp. 3393-3404, 2016.

[11] H. Doloi, A. Sawhney, K. C. Iyer, and S. Rentala, "Analysing Factors Affecting Delays in Indian Construction Projects," Int. J. Proj. Manag., vol. 30, pp. 479-489, 2012.

[12] M. A. Salam, H. J. Staines, D. J. Blackwood, and S. Sarkar, "Analysis of the Relationships Between Causes of Delay in Construction Projects in Bangladesh," in Proceeding of 17th Annual ARCOM Conference, 5-7 September, University of Salford, $U K, 2001$, vol. 1, no. September, pp. 619-28.

[13] K. Wong and V. Vimonsatit, "A Study of the Factors Affecting Construction Time in Western Australia," Sci. Res. Essays, vol. 7, no. 40, pp. 3390-3398, 2012.

[14] L. Van Truong, N. M. Sang, and N. T. Viet, "A Conceptual Model of Delay Factors affecting Government Construction Projects," ARPN J. Sci. Technol., vol. 5, no. 2, pp. 92-100, 2015.

[15] J. F. Hair, W. C. Black, B. J. Babin, and R. E. Anderson, Multivariate Data Analysis (7th Edition), 7th ed. Pearson Prentice Hall, 2010.

[16] N. N. Zainol, "A Structural Model of Green Cleaning Components and Requirements for Green Buildings," Universiti Teknologi Malaysia, 2016.

[17] D. W. Barclay and R. Thompson, "The Partial Least Squares (PLS) Approach to Causal Modelling: Personal Computer Adaptation and Use as an Illustration," Technol. Stud., vol. 2, no. 2, pp. 286-309, 1995.

[18] J.-B. Yang and S.-F. Ou, "Using Structural Equation Modeling to Analyze Relationships among Key Causes of Delay in Construction," Can. J. Civ. Eng., vol. 35, no. 4, pp. 321-332, 2008.

[19] M. Haenlein and A. M. Kaplan, "A Beginner's Guide to Partial Least Squares Analysis,” Underst. Stat., vol. 3, no. 4, pp. 283-297, 2004.

[20] P. B. Lowry and J. Gaskin, "Partial Least Squares (PLS) Structural Equation Modeling (SEM) for Building and Testing Behavioral Causal Theory: When to Choose It and How to Use It," IEEE Trans. Prof. Commun., vol. 57, no. 2, pp. 123-146, 2014.

[21] D. Gefen, D. W. Straub, and M.-C. Boudreau, "Structural Equation Modeling and Regression: Guidelines for Research Practice," Commun. Assoc. Inf. Syst., vol. 4, 2000.

[22] L. Trinchera and G. Russolillo, "On The Use of Structural Equation Models and PLS Path Modeling to Build Composite Indicators,' 2010.

[23] R. B. Kline, Exploratory and Confirmatory Factor Analysis. New York: Routledge: In Y. Petscher \& C. Schatsschneider. (Eds.), Applied Quantitative Analysis in the Social Sciences, 2013.

[24] H. Doloi, "Analysis of Pre-qualification Criteria in Contractor Selection and their Impacts on Project Success," Constr. Manag. Econ., vol. 27, no. 12, pp. 1245-1263, 2009.

[25] A. S. Hussein, "Penelitian Bisnis dan Manajemen Menggunakan Partial Least Squares (PLS) dengan SmartPLS 3.0," University of Brawijaya, 2015

[26] W. W. Chin, B. L. Marcolin, and P. Newsted, "A Partial Least Squares Latent Variable Modeling Approach for Measuring Interaction Effects: Results from a Monte Carlo Simulation Study and Voice Mail Emotion/Adoption Study," in Proceedings of the Seventeenth International Conference on Information Systems, 1996, pp. 21-41.

[27] R. M. Baron and D. a. Kenny, "The Moderator-Mediator Variable Distinction in Social The Moderator-Mediator Variable Distinction in Social Psychological Research: Conceptual, Strategic, and Statistical Considerations," J. Pers. Soc. Psychol., vol. 51, no. 6, pp. 1173-1182, 1986.

[28] H. Aguinis, J. R. Edwards, and K. J. Bradley, "Improving Our Understanding of Moderation and Mediation in Strategic Management Research," Organ. Res. Methods, vol. 20, no. 4, pp. 
$665-685,2017$.

[29] D. Iacobucci, "Everything You Always Wanted to Know about SEM (Structural Equations Modeling) but were Afraid to Ask," $J$. Consum. Psychol., vol. 19, pp. 673-680, 2009.

[30] R. Ho, Handbook of Univariate And Multivariate Data Analysis And Interpretation With SPSS. Boca Raton, Florida: Chapman \& Hall/CRC Taylor \& Francis Group, 2006

[31] D. Gefen and D. Straub, "A Practical Guide To Factorial Validity Using PLS- Graph: Tutorial and Annotated Example," Commun. Assoc. Inf. Syst., vol. 16, pp. 91-109, 2005.

[32] C. Nitzl, J. L. Roldan, and G. Cepeda, "Mediation Analysis in Partial Least Squares Path Modeling: Helping Researchers Discuss More Sophisticated Models," Ind. Manag. Data Syst., vol. 116, no. 9, pp. 1849-1864, 2016

[33] D. A. Kenny and C. M. Judd, "Estimating the Linear and Interactive Effects of Latent Variables," Am. Psychol. Assoc. Inc., vol. 96, no. I, pp. 201-210, 1984

[34] K. G. Jöreskog and F. Y. Wallentin, Nonlinear Structural Equation Models: The Kenny-Judd model with Interaction Effects. Lawrence Erlbaum Associates, 1996.

[35] K. G. Jöreskog and D. Sörbom, LISREL 8: Structural Equation Modeling with the SIMPLIS Command Language. Lincolnwood, USA, 1993.

[36] Arbuckle and J. L, Amos 18 User's Guide. USA, 2009.

[37] B. M. Byrne, Structural Equation Modeling With EQS: Basic Concepts, Applications, 2nd Editio. New York: Lawrence Erlbaum Associates, Inc., 2006.

[38] J. Henseler, C. M. Ringle, and M. Sarstedt, Using Partial Least Squares Path Modeling in International Advertising Research: Basic Concepts and Recent Issues. Edward Elgar, 2012.

[39] Nebojša St. Davčik, "The Use And Misuse Of Structural Equation Modeling in Management Research," 2007.

[40] H. Hwang, N. K. Malhotra, Y. Kim, M. A. Tomiuk, and S. Hong, "A Comparative Study on Parameter Recovery of Three Approaches to Structural Equation Modeling," J. Mark. Res., vol 47 , no. 4, pp. 699-712, 2010

[41] H. Hwang and Y. Takane, "Generalized Structured Component Analysis," Psychom. Sociiety, vol. 69, no. 1, pp. 81-99, 2004.

[42] F. Buckler and T. Hennig-Thurau, "Identifying Hidden Structures in Marketing's Structural Models Through Universal Structure Modeling: An Explorative Bayesian Neural Network Complement to LISREL and PLS," Mark. Res. Manag., vol. 4, no. 2, pp. 47-66, 2008

[43] J. F. Hair, M. Sarstedt, T. M. Pieper, and C. M. Ringle, "Applications of Partial Least Squares Path Modeling in Management Journals: A Review of Past Practices and Recommendations for Future Applications," Long Range Plann., vol. 45, no. 5-6, pp. 320-340, 2012.

[44] A. Khamis, N. K. K. Kamarudin, M. E. Nor, S. Saharan, and N. M. Asrah, "Covariance Based and Partial Least Square Structural Equation Modeling to Model Job Satisfaction among Lecturers," Sci. Res. J., vol. 5, no. 3, pp. 19-28, 2017.

[45] J. Joseph F. Hair, G. T. M. Hult, C. M. Ringle, and M. Sarstedt, $A$ Primer on Partial Least Squares Structural Equation Modeling (PLS-SEM). Sage Publications, 2014

[46] C. Fornell and F. L. Bookstein, "Two Structural Equation Models: LISREL and PLS Applied to Consumer Exit-Voice Theory," $J$. Mark. Res., vol. 19, no. 4, pp. 440-452, 1982

[47] J. F. Hair, C. M. Ringle, and M. Sarstedt, "Partial Least Squares Structural Equation Modeling: Rigorous Applications, Better Results and Higher Acceptance," Long Range Plann., vol. 46, pp. $1-12,2013$.

[48] K. Bollen and R. Lennox, "Conventional Wisdom on Measurement: A Structural Equation Perspective," Psychol. Bull., vol. 110, no. 2, pp. 305-314, 1991

[49] T. Coltman, T. M. Devinney, D. F. Midgley, and S. Venaik, "Formative versus Reflective Measurement Models: Two Applications of Erroneous Measurement," J. Bus. Res., vol. 61, no. 12, pp. 1250-1262, 2008.

[50] D. X. Peng and F. Lai, "Using Partial Least Squares in Operations Management Research: A Practical Guideline and Summary of Past Research," J. Oper. Manag., vol. 30, no. 6, pp. 467-480, 2012.

[51] B. Schneider, M. Carnoy, J. Kilpatrick, W. H. Schmidt, and R. J. Shavelson, Estimating Causal Effects Using Experimental and Observational Designs. Washington, D.C.: The Governing Board of the American Educational Research Association Grant Program, 2007.

[52] K. G. Jöreskog, "Some contributions to maximum likelihood factor analysis," Psychometrika, vol. 32, no. 4, pp. 443-482, 1967.

[53] J. F. Hair, C. M. Ringle, and M. Sarstedt, "PLS-SEM: Indeed a Silver Bullet," J. Mark. Theory Pract., vol. 19, no. 2, pp. 139-152, 2011.

[54] C. T. B. College, W. W. Chin, B. L. Marcolin, and P. R. Newsted, "A Partial Least Squares Latent Variable Modeling Approach for Measuring Interaction Effects: Results from a Monte Carlo Simulation Study and an Electronic-Mail Emotion / Adoption Study," vol. 14, no. 2, pp. 189-217, 2003.

[55] A. Boomsma and J. J. Hoogland, The Robustness of LISREL Modeling Revisited. A Festschrift in honor of Karl Jöreskog, 2001.

[56] J. Henseler and W. W. Chin, "A Comparison of Approaches for the Analysis of Interaction Effects between Latent Variables using Partial Least Squares Path Modeling," Struct. Equ. Model., vol. 17, pp. $82-109,2010$.

[57] B. Xiong, M. Skitmore, and B. Xia, "A Critical Review of Structural Equation Modeling Applications in Construction Research," Autom. Constr., vol. 49, no. PA, pp. 59-70, 2015.

[58] K. Molenaar, S. Washington, and J. Diekmann, "Structural Equation Model of Construction Contract Dispute Potential," $J$. Constr. Eng. Manag., vol. 126, no. 4, pp. 268-277, 2000.

[59] L. Zhang and X. Huo, "The Impact of Interpersonal Conflict on Construction Project Performance: A Moderated Mediation Study from China," Int. J. Oper. Prod. Manag., vol. 26, no. 4, pp. 479498,2015

[60] S. Helm, A. Eggert, and I. Garnefeld, "Modeling the Impact of Corporate Reputation on Customer Satisfaction and Loyalty Using Partial Least Squares," in In Handbook of Partial Least Squares, Berlin, Heidelberg: Springer, 2010, pp. 515-534.

[61] W. Oetomo, "Model of Influence to Delay Construction Projects of Multistoried Buildings Using Multi-Dimensional of Stage with Analysis of Second Order," J. Basic Appl. Sci. Res., vol. 6, no. 1, pp. $15-25,2016$.

[62] S. A. Assaf and S. Al-Hejji, "Causes of Delay in Large Construction Projects," Int. J. Proj. Manag., vol. 24, pp. 349-357, 2006.

[63] Z. Shehu, I. R. Endut, A. Akintoye, and G. D. Holt, "Cost Overrun in the Malaysian Construction Industry Projects: A Deeper Insight," Int. J. Proj. Manag., vol. 32, pp. 1471-1480, 2014.

[64] C. B. Astrachan, V. K. Patel, and G. Wanzenried, "A Comparative Study of CB-SEM and PLS-SEM for Theory Development in Family Firm Research,” J. Fam. Bus. Strateg., vol. 5, pp. 116-128, 2014. 